\title{
Perancangan Miniatur Pintu Air Otomatis Berbasis Sensor Water Level dan Arduino Uno pada Sistem Irigasi Persawahan
}

\author{
Muhaimin $^{1}$, Bengawan Alfaresi ${ }^{2 *}$, Feby Ardianto $^{3}$ \\ 1,2,3 Program Studi Teknik Elektro, Fakultas Teknik, Universitas Muhammadiyah Palembang, Palembang \\ *Koresponden email: begawan_alfarezi@um-palembang.ac.id
}

Diterima: 13 Juli 2021

Disetujui: 26 Juli 2021

\begin{abstract}
The arrangement of the floodgates for rice irrigation canals is currently still using the manual method. This is very burdensome for farmers because it requires time and energy. Therefore, we need a sluice in the irrigation canal that can be done automatically. The purpose of this research is to design a miniature sluice system that can automate the sluice gate in opening and closing the sluice gate based on the water level limit of the channel. The method used in this study is the use of Arduino Uno as data storage, a servo motor that functions as a floodgate controller, a water level sensor to open the floodgate and an ultrasonic sensor that functions to determine the water level. The results of the tool testing in the research of the miniature automatic sluice gate that has been designed, namely the automatic sluice gate will open when the water sensor at the top is exposed to water. The ultrasonic sensor will measure the distance between the sensor and the water surface to make a decision to close the floodgate. If the sensor distance with the water surface is still $>14 \mathrm{~m}$, then the floodgate will open 1800, if the sensor distance with the water surface is $>4 \mathrm{~cm}$ and $<14 \mathrm{~cm}$, then the floodgate will open 900 and if the distance between the sensor and the water surface is $<4 \mathrm{~cm}$, then the floodgate will be closed.
\end{abstract}

Keywords: water gate, Arduino Uno, water sensor, servo motor, ultrasonic sensor

\begin{abstract}
Abstrak
Pengaturan pintu air saluran irigasi persawahan saat ini masih menggunakan metode manual. Hal tersebut sangat memberatkan para petani karena memerlukan waktu dan tenaga yang. Oleh karena itu, diperlukan suatu pintu air pada saluran irigasi yang dapat dilakukan secara otomatis. Tujuan dari penelitian ini yaitu merancang miniatur sistem pintu air yang dapat melakukan secara otomatisasi pintu air dalam pembukaan dan penutupan pintu air berdasarkan batas ketinggian air saluran. Metode yang digunakan pada penelitian ini yaitu penggunaan Arduino Uno sebagai penyimpanan data, motor servo yang berfungsi pengendali pintu air, sensor water level untuk membuka pintu air serta sensor ultrasonik yang berfungsi untuk menentukan ketinggian air. Hasil pengujian alat pada penelitian dari miniatur pintu air otomatis yang telah dirancang yaitu pintu air otomatis akan membuka ketika sensor air pada bagian atas terkena air. Sensor ultrasonik akan mengukur jarak antara sensor dengan permukaan air untuk melakukan keputusan penutupan pintu air. Apabila jarak sensor dengan permukaan air masih $>14 \mathrm{~m}$, maka pintu air akan terbuka $180^{\circ}$, jika jarak sensor dengan permukaan air $>4 \mathrm{~cm}$ dan $<14 \mathrm{~cm}$, maka pintu air akan terbuka $90^{\circ}$ dan jika jarak antara sensor dengan permukaan air $<4 \mathrm{~cm}$, maka pintu air akan tertutup.
\end{abstract}

Kata Kunci: pintu air, Arduino Uno, sensor air, motor servo, sensor ultrasonik

\section{Pendahuluan}

Hal yang paling mendasar pada sistem persawahan yaitu pada sistem irigasi atau pengairan. Sistem irigasi merupakan salah satu faktor penentu keberhasilan pada sistem pertanian maupun budidaya tanaman. Sistem irigasi yang baik dapat meningkatkan probabilitas keberhasilan dari suatu sistem pertanian[1]. Saat ini sistem irigasi di persawahan untuk menutup dan membuka pintu masyarakat masih menggunakan cara manual yaitu dengan berjalan membuka atau menutup pintu 1 dengan yang laninya [2]. Pengembangan dari pintu air otomatis ini yaitu untuk menutupi kekurangan dari cara manual yang sangat tergantung pada sistem penjadwalan manual oleh penjaga pintu. Faktor kelalaian sering terjadi sehingga menyebabkan tuas penutup-pembuka pintu tidak dapat berfungsi dengan baik sehingga air tidak terkontrol, meluber dan tidak mengalir ke sistem persawahan [3], sehingga dapat menyebabkan kerugian pada masyarakat khususnya pada hasil dari persawahan dikarenakan air dapat mengalami kekurangan maupun kelebihan yang berakibat air meluap dikarenakan sistem penutupan pintu yang terlambat. Untuk mengatasi hal tersebut diperlukan adanya sistem pintu air yang dapat dikendalikan secara otomatis dengan memanfaatkan penggunaan sensor 
kontrol Arduino Uno dan ultrasonik untuk sistem irigasi persawahan dalam skala mikro [4]. Dengan penggunaan sistem otomatisasi ini diharapkan dapat mengurangi campur tangan manusia yang sering kali memiliki beberapa kelemahan seperti kelalaian dalam melakukan buka tutup sistem pintu air, sehingga system persawahan dapat dikendalikan secara efektif dan efisien [5]. Sistem pengendalian pintu air secara otomatis dapat memudahkan masyarakat dalam menjaga tingkat kestabilan air dengan cara memanfaatkan otomatisasi pintu air dengan meminimalisir campur tangan usaha manusia yang dilakukan secara manual [6].

Sistem pengairan atau Irigasi merupakan suatu skema bekerja dalam usaha mendatangkan sumber air dan melakukan suatu strategi pengaliran air dengan pembuatan saluran maupun bangunan kepada persawahan secara teratur dan melakukan pembuangan air sisa perairan yang sudah tidak digunakan lagi dengan baik [7]. Oleh karena itu, penggunaan air pada sistem irigasi persawahan harus dapat terkendali dengan baik agar memberikan efek yang positif bagi pengembangan maupun hasil dibidang persawahan dan pertanian yang hasilnya dapat ditentukan dari sistem pengairan yang stabil [8],[9]. Pada dasarnya air dikatakan tersedia bagi tanaman apabila air yang berada dalam pori-pori tanah tersebut dapat diambil oleh akar tanaman [10]. Agar supaya memiliki jenis tanah yang subur serta hasil alam yang mempunyai keanekaragaman khususnya di bidang persawahan dan pertanian [11]. Sehingga diperlukan suatu sistem yang dapat mengendalikan pendistribusian air secara merata dan cukup mengondisikan kesuburan tanah dalam jumlah yang cukup tinggi bagi tanaman secara merata, serta meminimalisir adanya genangan air yang berlebihan agar tidak mengganggu kehidupan tanaman [12] [13].

Perkembangan teknologi yang pesat telah membawa pengaruh pada kehidupan masyarakat dalam kehidupan sehari-hari. Teknologi sangat membantu terhadap berbagai permasalahan yang dihadapi oleh masyarakat. Pada sistem irigasi dengan memanfaatkan pintu air otomatis merupakan suatu konstruksi bangunan dan juga instalasi yang digunakan untuk membuka dan menutup serta dapat mengatur aliran air yang mengalir pada sistem irigasi persawahan berdasarkan pada ketinggian air [14]. Penggunaan teknologi dalam sistem irigasi diharapkan dapat memudahkan dan meningkatkan efektivitas dari masyarakat dalam mengelola irigasi persawahan.

Tujuan dari penelitian ini yaitu untuk membantu petani dan pekebun agar lebih mudah mengoperasikan pintu air pada irigasi persawahan dan perkebunan guna untuk mendapatkan air secara teratur dengan adanya lahan pasang surut. Pada sistem pintu air otomatis dengan ketinggian air memanfaatkan komponen-komponen elektronik yaitu Arduino Uno, sensor air, sensor ultrasonik, motor servo, LCD dan LED (Light Emitting Diode). Dalam hal ini arduino ini sebagai kontrol ketinggian air, dibantu sensor ultrasonik sebagai pembaca sistem yang sudah terintegrasi dan motor servo sebagai penggerak pada pintu air [15].

\section{Metode Penelitian}

Adapun pada penelitian ini dibutuhkan beberapa alat dan yang digunakan dalam perancangan bangun pintu air otomatis pada irigasi persawahan menggunakan mikrokontroler. Cara kerja mikrokontroler dapat dilihat pada diagram alir (flowchart) dimana sensor air di dalam akuarium telah dipasang satu buah. Pada saat ketinggian air 4-14 cm maka pintu air terbuka $90^{\circ}$ sementara pada saat air dengan ketinggian $>14 \mathrm{~cm}$ maka pintu terbuka $180^{\circ}$. Jika sensor air telah menyentuh air maka sensor air memerintahkan motor servo untuk menutup pintu air secara sempurna. Untuk flow diagram pintu air otomatis dapat dilihat pada Gambar 1. 


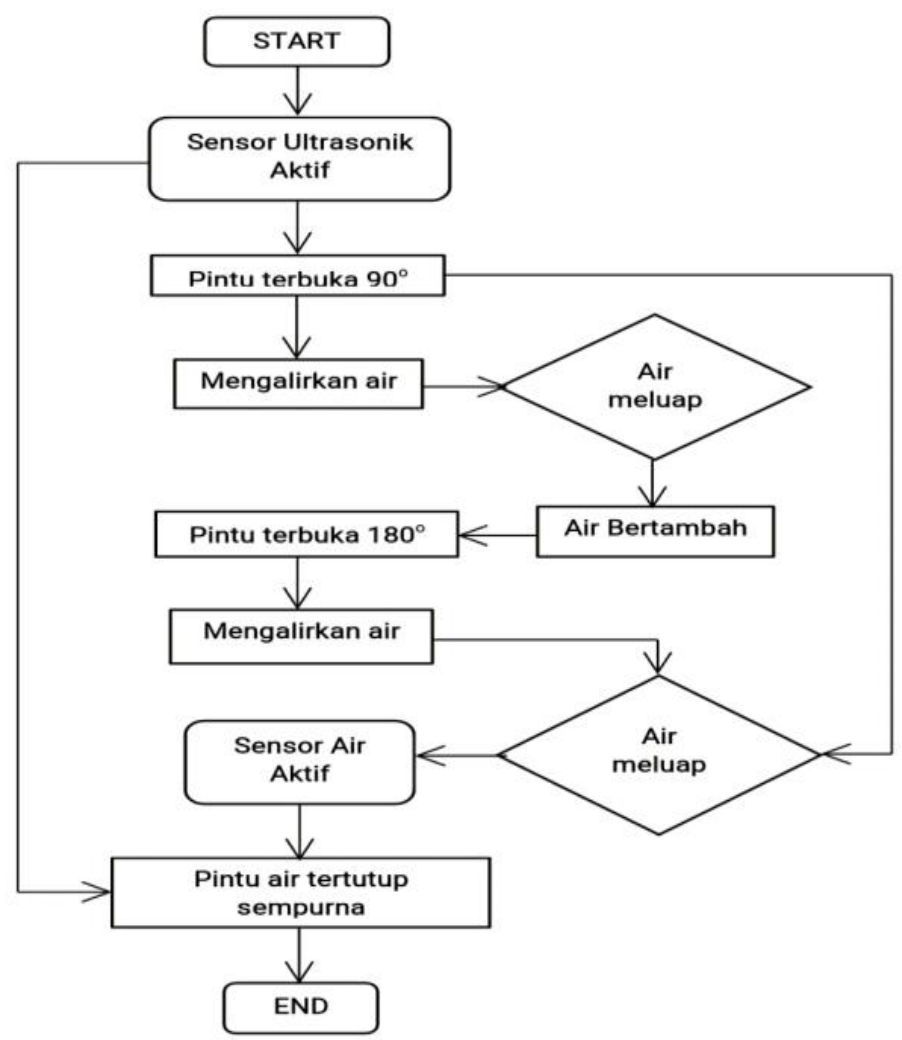

Gambar 1. Flowchart Cara Kerja Pada Sensor Air Sumber: Peneliti

\section{Flowchart Simulasi Pintu Air Otomatis}

Cara kerja flowchart simulasi pintu air otomatis prototype sistem pada Gambar $\mathbf{2}$ dimulai dari alat siap. Kemudian informasi ketinggian air ditampilkan pada LCD display berdasarkan hasil pengukuran sensor ultrasonik yang dipasang pada bagian dinding samping pintu air.

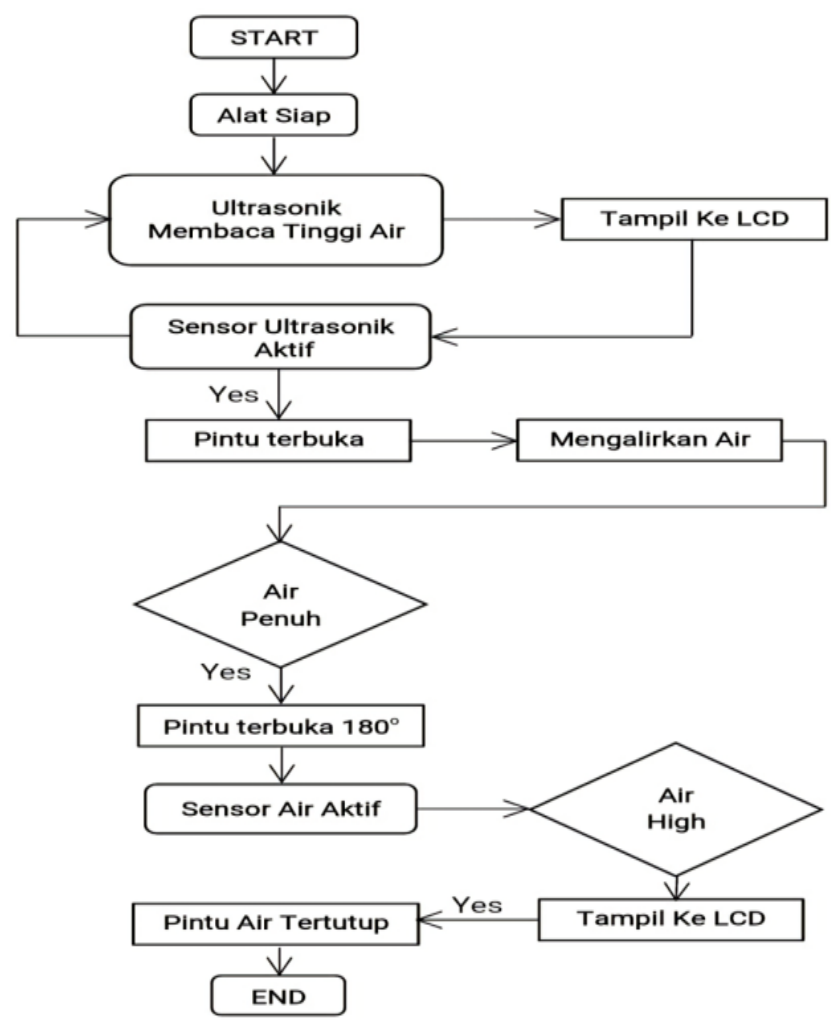

Gambar 2. Flowchart simulasi pintu air otomatis Sumber: Peneliti 
Pada saat air dengan ketinggian $<4 \mathrm{~cm}$ maka LED yang menyala berwarna merah dan LCD menunjukkan bahwa pintu tertutup. Pada saat air dengan ketinggian 4-14cm maka LED yang menyala berwarna kuning, motor servo membuka pintu air $90^{\circ}$ dan LCD menunjukkan bahwa pintu terbuka. Pada saat air dengan ketinggian $>14 \mathrm{~cm}$ maka LED yang menyala berwarna hijau, motor servo membuka pintu air $180^{\circ}$ dan LCD menunjukkan bahwa pintu terbuka. Jika sensor air telah menyentuh air maka motor servo menutup pintu air secara sempurna.

\section{Hasil dan Pembahasan Hasil Perancangan}

Hasil perancangan dari keseluruhan rancang bangun pintu air otomatis berbasis Arduino Uno berupa miniatur pintu buka tutup yang terbuat dari kotak akuarium. Pada miniatur buka tutup pintu air otomatis ini menggunakan bahan Kaca dan pada miniatur terdapat beberapa komponen seperti sensor air, sensor ultrasonik, dan motor DC.

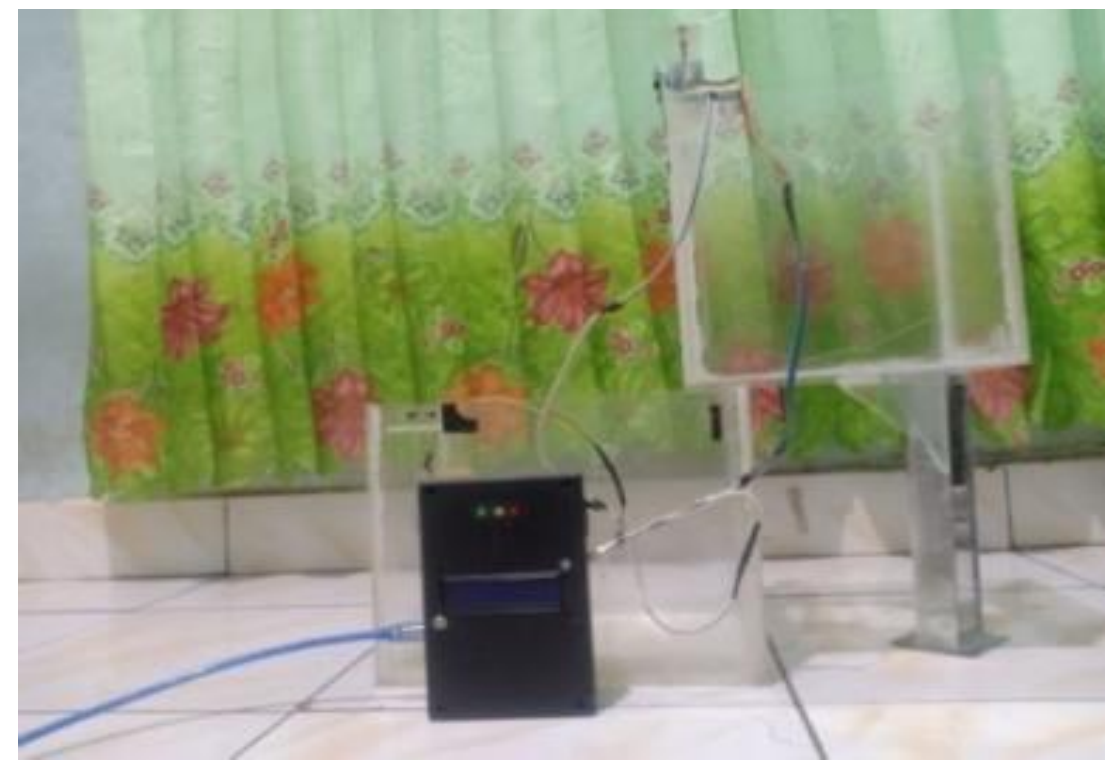

Gambar 3. Hasil Perancangan

Sumber: Peneliti

Pada Gambar 3 menunjukkan miniatur pintu air otomatis. Saluran irigasi yang mengalir dari atas ke bawah diasumsikan menjadi 2 bagian yaitu bagian tinggi (high) dan bagian rendah (low). Kotak yang di atas diasumsikan merupakan aliran air yang lebih tinggi, sedangkan kotak yang di bawah diasumsikan merupakan bagian pengairan dengan kondisi yang lebih rendah. Kotak hitam merupakan komponen dari Arduino Uno yang terhubung dengan sensor water level, sensor ultrasonik yang diletakkan pada bagian atas dan pada bagian bawah, Selain itu, Arduino Uno juga terhubung dengan motor servo yang berguna untuk melakukan buka-tutup pintu saluran irigasi otomatis. Pengujian penelitian ini dibagi menjadi dua yaitu pengujian sensor ultrasonik dan pengujian alat secara keseluruhan.

\section{Pengujian Sensor Ultrasonik}

Sensor ultrasonik adalah alat yang dapat digunakan untuk mengukur jarak berdasarkan gelombang pantulan (frekuensi). Kita dapat mengetahui jarak suatu benda dengan menggunakan sensor ultrasonik. Dalam pengaplikasianya, sensor ultrasonik dijadikan sebuah input pada mikrokontroler.

Pada penelitian ini dilakukan serangkaian uji coba sensor ultrasonik jenis HC-SR04 yang dikombinasikan dengan pengontrol berupa Arduino Uno. Pengujian ini bertujuan untuk menguji kepekaan sensor ultrasonik pada jarak 0 sampai $15 \mathrm{~cm}$. Adapun untuk prosedur pengujian sensor ultrasonik yang dilakukan adalah pada tahap ini adalah sebagai berikut:

1. Mempersiapkan peralatan

2. VCC dan GND disambungkan Arduino Uno pada pin positif 5v dan negatif GND.

3. Menghubungkan pin echo ultrasonik dengan pin D7 Arduino, serta menghubungkan pin trigger ultrasonik dengan D8 Arduino.

4. Menghubungkan USB Arduino dengan laptop.

5. Upload program sensor ultrasonik untuk arduino. 


\section{Gambar 4.}

Untuk kode program yang digunakan pada tahap pengujian sensor ultrasonik ini dapat dilihat pada

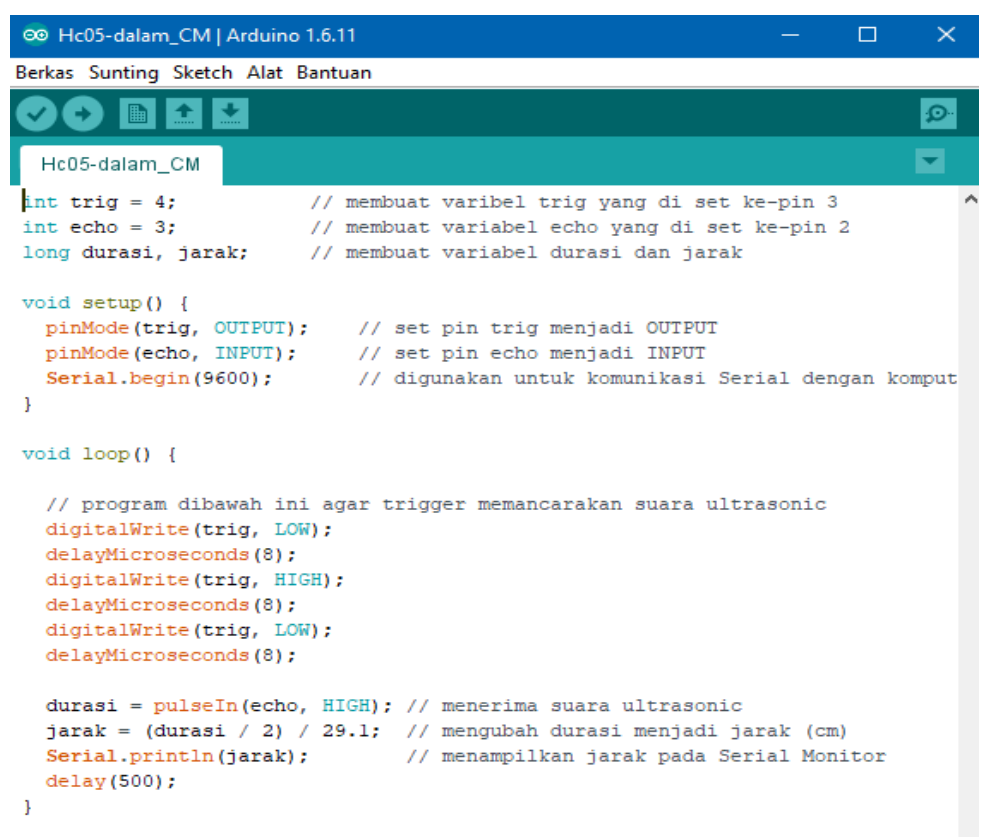

Gambar 4. Kode Program Pengujian sensor ultrasonik Sumber: Peneliti

Program pengujian sensor ultrasonik dapat dilihat pada Gambar 4, pin yang digunakan adalah pin 4 dan 3 pada Arduino. Pada sensor ultrasonik terdapat 4 pin yang dihubungkan ke Arduino Uno dengan keterangan pin Vcc, Gnd, Echo, dan Trig. Pin vcc berfungsi sebagai suplai tegangan $+5 \mathrm{~V}$ dan pin Gnd berfungsi sebagai suplai $0 \mathrm{~V}$, sedangkan pin echo dan trig berfungsi sebagai pembacaan dan pengiriman data hasil pembacaan pada sensor ultrasonik. Hasil pengujian sensor ultrasonik dapat dilihat pada Tabel 1.

Tabel 1. Pengujian sensor ultrasonik

\begin{tabular}{ccc}
\hline No. & $\begin{array}{c}\text { Jarak Pengujian } \\
\text { Sensor }(\mathrm{Cm})\end{array}$ & $\begin{array}{c}\text { Waktu } \\
(\mu s)\end{array}$ \\
\hline 1. & 2 & 155 \\
2. & 4 & 255 \\
3. & 6 & 360 \\
4. & 8 & 477 \\
5. & 10 & 594 \\
6. & 12 & 710 \\
7. & 14 & 826 \\
8. & 16 & 942 \\
\hline \multicolumn{3}{c}{}
\end{tabular}

Sumber: Hasil penelitian

Berdasarkan Tabel 1 pengujian sensor ultrasonik dapat dilihat bahwa terdapat 8 buah data pengujian dengan kelipatan jarak sebesar $2 \mathrm{~cm}$. Untuk nilai jarak maksimal yang dilakukan pada pengujian ini adalah sebesar $16 \mathrm{~cm}$. Nilai parameter yang diuji coba pada tahap ini adalah waktu pengiriman data dari pin trigger ke pin echo sebagai proses pembacaan sensor.

\section{Perhitungan Jarak Sensor}

Setelah mengetahui tingkat sensitivitas pada sensor ultrasonik, langkah selanjutnya adalah melakukan perhitungan jarak pada sensor. Hal ini bertujuan untuk membandingkan data hasil pengukuran dengan data hasil perhitungan sebagai tahap awal dalam menentukan nilai error/kesalahan yang terjadi pada sensor ultrasonik. Berikut merupakan perhitungan jarak sensor ultrasonik dengan menggunakan persamaan sebagai berikut:

$$
S=\frac{(v \times t)}{2}
$$


Dimana $\mathrm{S}$ adalah jarak obyek (m), v adalah kecepatan gelombang ultrasonik $(340 \mathrm{~m} / \mathrm{s})$ dan $\mathrm{t}$ adalah waktu (s). Dari hasil perhitungan dengan menggunakan persamaan (1) diperoleh hasil sebagai berikut:

1. Data ke-1 (jarak terukur $2 \mathrm{~cm}$ )

$$
\begin{aligned}
& s=\frac{340 \mathrm{~m} / \mathrm{s}}{2} \times 155 \mu \mathrm{s} \\
& s=\frac{340 \mathrm{~m} / \mathrm{s}}{2} \times 0,000155 \mathrm{~s} \\
& s=2,63 \mathrm{~cm}
\end{aligned}
$$

2. Data ke-2 (jarak terukur $4 \mathrm{~cm}$ )

$$
\begin{aligned}
& s=\frac{340 \mathrm{~m} / \mathrm{s}}{2} \times 255 \mu \mathrm{s} \\
& s=\frac{340 \mathrm{~m} / \mathrm{s}}{2} \times 0,000255 \mathrm{~s} \\
& s=4,33 \mathrm{~cm}
\end{aligned}
$$

3. Data ke-3 (jarak terukur $6 \mathrm{~cm}$ )

$$
\begin{aligned}
& s=\frac{340 \mathrm{~m} / \mathrm{s}}{2} \times 360 \mu \mathrm{s} \\
& s=\frac{340 \frac{\mathrm{m}}{\mathrm{s}}}{2} \times 0,000360 \mathrm{~s} \\
& s=6,12 \mathrm{~cm}
\end{aligned}
$$

4. Data ke-4 (jarak terukur $8 \mathrm{~cm}$ )

$$
\begin{aligned}
& s=\frac{340 \mathrm{~m} / \mathrm{s}}{2} \times 477 \mu \mathrm{s} \\
& s=\frac{340 \mathrm{~m} / \mathrm{s}}{2} \times 0,000477 \mathrm{~s} \\
& s=8,10 \mathrm{~cm}
\end{aligned}
$$

5. Data ke-5 (jarak terukur $10 \mathrm{~cm}$ )

$$
\begin{aligned}
& s=\frac{340 \mathrm{~m} / \mathrm{s}}{2} \times 594 \mu \mathrm{s} \\
& s=\frac{340 \mathrm{~m} / \mathrm{s}}{2} \times 0,000594 \mathrm{~s} \\
& s=10,09 \mathrm{~cm}
\end{aligned}
$$

6. Data ke-6 (jarak terukur $12 \mathrm{~cm}$ )

$$
\begin{aligned}
& s=\frac{340 \mathrm{~m} / \mathrm{s}}{2} \times 710 \mu \mathrm{s} \\
& s=\frac{340 \mathrm{~m} / \mathrm{s}}{2} \times 0,000710 \mathrm{~s} \\
& s=12,07 \mathrm{~cm}
\end{aligned}
$$

7. Data ke-7 (jarak terukur $14 \mathrm{~cm}$ )

$$
\begin{aligned}
& s=\frac{340 \mathrm{~m} / \mathrm{s}}{2} \times 826 \mu \mathrm{s} \\
& s=\frac{340 \mathrm{~m} / \mathrm{s}}{2} \times 0,000826 \mathrm{~s} \\
& s=14,04 \mathrm{~cm}
\end{aligned}
$$

8. Data ke-8 (jarak terukur $16 \mathrm{~cm}$ )

$$
\begin{aligned}
& s=\frac{340 \mathrm{~m} / \mathrm{s}}{2} \times 942 \mu \mathrm{s} \\
& s=\frac{340 \mathrm{~m} / \mathrm{s}}{2} \times 0,000942 \mathrm{~s} \\
& s=16,01 \mathrm{~cm}
\end{aligned}
$$

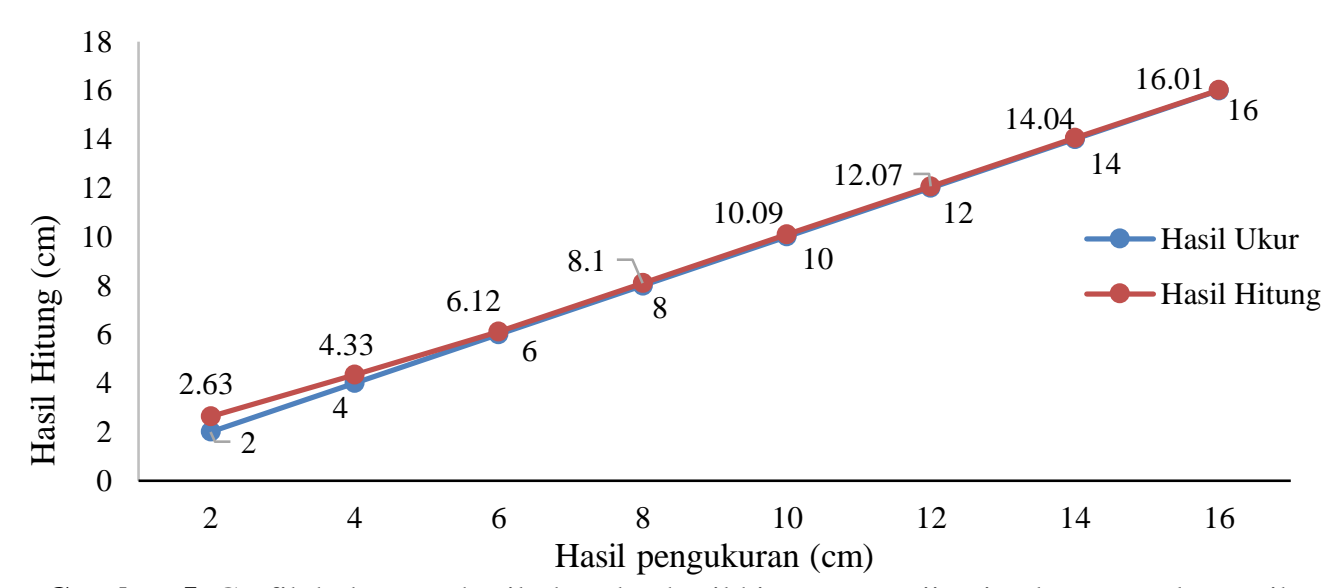

Gambar 5. Grafik hubungan hasil ukur dan hasil hitung pengujian jarak sensor ultrasonik Sumber: Hasil penelitian

Berdasarkan Gambar 5 grafik hubungan hasil ukur dengan hasil hitung pada pengujian sensor ultrasonik dapat dilihat bahwa perbedaan nilai yang dihasilkan tidak terlalu signifikan, terlihat pada gambar bahwa nilai selisih terbesar terjadi pada data ke-1 dengan nilai sebesar $0,6 \mathrm{~cm}$. Sementara untuk nilai selisih terkecil antara hasil ukur dengan hasil hitung terdapat pada data ke-8 dengan nilai selisih sebesar 0,01 cm.

\section{Perhitungan Error Sensor}

Setelah mendapatkan nilai perhitungan, langkah selanjutnya adalah melakukan perhitungan error sensor ultrasonik. Berikut merupakan perhitungan mencari nilai error pada sensor ultrasonik dapat menggunakan persamaan sebagai berikut:

$$
\operatorname{error}(\%)=\frac{\text { Nilai perhitungan }- \text { Nilai Eksak }}{\text { Nilai Eksak }} \times 100 \%
$$


Dimana error (\%) merupakan persentase error kesalahan, nilai perkiraan yaitu nilai estimasi perhitungan, dan nilai eksak yaitu nilai asli yang didapatkan pada pengukuran. Dengan persamaan (2), perhitungan error untuk tiap-tiap data adalah sebagai berikut:

1. Data ke-1 (jarak $2 \mathrm{~cm})$

$$
\begin{aligned}
& e(\%)=\frac{|2,63-2|}{2} \times 100 \% \\
& e(\%)=0,315 \%
\end{aligned}
$$

2. Data ke-2 (jarak $4 \mathrm{~cm})$

$$
\begin{aligned}
& e(\%)=\frac{|4,33-4|}{4} \times 100 \% \\
& (\%)=0,082 \%
\end{aligned}
$$

3. Data ke-3 (jarak $6 \mathrm{~cm})$

$$
\begin{aligned}
& e(\%)=\frac{|6,12-6|}{6} \times 100 \% \\
& e(\%)=0,002 \%
\end{aligned}
$$

4. Data ke-4 (jarak $8 \mathrm{~cm})$

$$
\begin{aligned}
& e(\%)=\frac{|8,10-8|}{8} \times 100 \% \\
& e(\%)=0,012 \%
\end{aligned}
$$

5. Data ke-5(jarak $10 \mathrm{~cm})$

$$
\begin{aligned}
& e(\%)=\frac{|10,09-10|}{10} \times 100 \% \\
& e(\%)=0,009 \%
\end{aligned}
$$

6. Data ke-6 (jarak $12 \mathrm{~cm})$

$$
\begin{aligned}
& e(\%)=\frac{|12,07-12|}{12} \times 100 \% \\
& e(\%)=0,005 \%
\end{aligned}
$$

7. Data ke-7 (jarak $42 \mathrm{~cm}$ )

$$
\begin{aligned}
& e(\%)=\frac{|14,04-14|}{14} \times 100 \% \\
& e(\%)=0,002 \%
\end{aligned}
$$

8. Data ke-7 (jarak $42 \mathrm{~cm})$

$$
\begin{aligned}
& e(\%)=\frac{|16,01-16|}{16} \times 100 \% \\
& e(\%)=0,0006 \%
\end{aligned}
$$

Tabel 2. Hasil perhitungan error sensor ultrasonik

\begin{tabular}{ccc}
\hline No & Jarak Sensor $(\mathrm{cm})$ & Error $(\%)$ \\
\hline 1. & 2 & 0,315 \\
2. & 4 & 0,082 \\
3. & 6 & 0,002 \\
4. & 8 & 0,012 \\
5. & 10 & 0,009 \\
6. & 12 & 0,005 \\
7. & 14 & 0,002 \\
8. & 16 & 0,0006 \\
\hline
\end{tabular}

Sumber: Hasil penelitian

Berdasarkan data perhitungan pada Tabel 2 hasil perhitungan error pada sensor ultrasonik dapat dilihat bahwa nilai terbesar terjadi pada data pertama yaitu dengan jarak sensor $2 \mathrm{~cm}$ dengan persentase error mencapai $0,315 \%$, sedangkan nilai error terkecil terjadi pada data terakhir yaitu dengan jarak sensor $16 \mathrm{~cm}$ dengan persentase error mencapai $0,0006 \%$. Dalam berbagai jarak pengujian diperoleh bahwa nilai error dari berbagai jarak masih di bawah $0,5 \%$. Berdasarkan hasil yang diperoleh maka dapat disimpulkan kondisi dari sensor yang digunakan masih dalam kondisi yang sangat baik.

\section{Analisa Sistem Keseluruhan}

Pada pengujian alat keseluruhan ini sebagai pengaplikasian dari pengujian mikrokontroler Arduino Uno, pengujian sensor air, pengujian motor servo, pengujian LED, dan pengujian sensor ultrasonik. Berikut merupakan Hasil data pengujian keseluruhan simulasi pintu air otomatis pada persawahan menggunakan sensor ari dan ultrasonik dapat dilihat pada Tabel 3.

Berdasarkan Tabel 3 hasil pengujian keseluruhan yang telah dilakukan dapat dilihat pada kondisi FULL yaitu ketika sensor air yang terletak pada bagian kotak aquarium atas terkena air, maka pintu otomatis akan membuka dan air akan turun dari aquarium atas ke aquarium bawah. Ketika sensor Ultrasonik yang terdapat pada aquarium bawah membaca ketinggian air dengan jarak antara air dan sensor ultrasonik $>14$ $\mathrm{cm}$, maka pintu air akan terbuka lebar dan lampu indikator menyala hijau dengan menggerakkan sudut servo $180^{\circ}$. 
Tabel 3. Hasil pengujian keseluruhan

\begin{tabular}{|c|c|c|c|c|c|c|c|}
\hline \multirow{2}{*}{ No } & \multirow{2}{*}{$\begin{array}{c}\text { Sensor Air (Kotak } \\
\text { Atas) }\end{array}$} & \multirow{2}{*}{$\begin{array}{l}\text { Sensor } \\
\text { Ultrasonik }\end{array}$} & \multirow{2}{*}{$\begin{array}{l}\text { Sudut } \\
\text { Servo }\end{array}$} & \multicolumn{2}{|c|}{ Lampu Indikator } & \multirow[b]{2}{*}{ Hijau } & \multirow{2}{*}{$\begin{array}{l}\text { Tampilan } \\
\text { LCD }\end{array}$} \\
\hline & & & & Merah & Kuning & & \\
\hline \multirow{3}{*}{1} & \multirow{3}{*}{ FULL (ON) } & $<4 \mathrm{~cm}$ & $0^{\circ}$ & ON & OFF & OFF & $\begin{array}{c}\text { Pintu } \\
\text { Tertutup }\end{array}$ \\
\hline & & $4-14 \mathrm{~cm}$ & $90^{\circ}$ & OFF & ON & OFF & $\begin{array}{c}\text { Pintu } \\
\text { Terbuka }\end{array}$ \\
\hline & & $>14 \mathrm{~cm}$ & $180^{\circ}$ & OFF & OFF & $\mathrm{ON}$ & $\begin{array}{c}\text { Pintu } \\
\text { Terbuka }\end{array}$ \\
\hline
\end{tabular}

Sumber: Hasil penelitian

Ketika ketinggian jarak antara permukaan air dan sensor air pada jarak $>4 \mathrm{~cm}$ dan $<14 \mathrm{~cm}$, maka lampu indikator akan menyala kuning dan sudut servo akan menutup pintu $90^{\circ}$. Jika jarak antara sensor air dengan permukaan air $<4 \mathrm{~cm}$, maka pintu air otomatis akan menutup kembali dengan menyalakan lampu indikator Merah.

\section{Kesimpulan}

Komponen yang digunakan dalam perancangan simulasi pintu air otomatis pada irigasi persawahan adalah sensor ultrasonik, sensor air, lampu indikator/LED, motor servo, LCD, power supply. Pengujian dilakukan dengan melakukan pengecekan pada seluruh kondisi komponen. Pengujian dimulai dari pengujian Arduino, pengujian motor servo, sensor air, pengujian LED, dan pengujian sensor ultrasonik. Berdasarkan dari keseluruhan pengujian komponen, dapat dikatakan keseluruhan komponen masih dalam kondisi sangat baik. Pada pengujian alat simulasi pintu air otomatis menggunakan sensor ultrasonik ini mengukur jarak ketinggian air terhadap sensor, apabila jarak sensor ke air $<4$ maka pintu tertutup $0^{\circ}$, jika jarak sensor ke air antara 4 sampai 14 maka pintu akan terbuka $90^{\circ}$, kemudian kondisi terakhir jika jarak antara air ke sensor $>14$ pintu akan terbuka $180^{\circ}$. Alat ini masih sebatas miniatur sebagai prototipe dari pintu air otomatis dan ke depannya akan diaplikasikan pada kondisi secara real di saluran irigasi persawahan.

\section{Referensi}

[1] S. Samsugi, Z. Mardiyansyah dan A. Nurkholis, "Sistem Pengontrol Irigasi Otomatis Menggunakan Mikrokontroler Arduino Uno," J. Teknologi Dan Sistem Tertanam, Vol. 1(1), hal. 17-22, 2020.

[2] C. D. A. Aswardi, "Rancang Bangun Buka Tutup Pintu Air Otomatis Pada Irigasi Sawah Berbasis Arduino Dan Monitoring Menggunakan Android," Vol. 6(1), hal. 167-178, 2020.

[3] A. Paundra, S. Akuwan, M. Hani dan W. Ari, "Sistem Kontrol Pintu Air Otomatis Berdasarkan Curah Hujan Menggunakan Sms Gateway Abstrak," hal. 1-4.

[4] M. Masykur, Irman Nurichsan R. F. Ginanjar, "Rancang Bangun Prototype Alat Buka Tutup Pintu Perairan Sawah Otomatis Bersekala Kecil Di Desa Majasari Menggunakan Arduino Uno," Jurnal, Vol. 11(1), 2020.

[5] H. Apriyanto, "Rancang Bangun Pintu Air Otomatis Menggunakan Water Level Float Switch Berbasis Mikrokontroler," J. Sisfokom (Sistem Inf. dan Komputer), Vol. 4(1), hal. 22, 2015, Doi: 10.32736/Sisfokom.V4i1.132.

[6] Surmayanti dan R. H. Zain, "Perancangan Sistem Buka-Tutup Pintu Air Otomatis Di Muara/Waduk Menggunakan Sensor Infra Red Dan Photo Dioda Dengan Tampilan LCD Berbasis Arduino Uno Atmega-328," J. Teknol. Inf. Pendidik., Vol. 9(1), hal. 153-162, 2016.

[7] B. T. W. Utomo dan H. Saifudi, "Prototiping Sistem Monitoring Ketinggian Air Dan Pengendalian Pintu Air Pada Jaringan Irigasi Berbasis Microkontroler Atmega16 Dengan Menggunakan Short Message Service (SMS),” J. Ilm. Teknol. Inf. Asia, Vol. 8(1), hal. 59-69, 2014.

[8] Wiranto, B. I. Setiawan dan S. K. Saptomo, "Sistem Kontrol Irigasi Otomatis Nirkabel," J. Irigasi, Vol. 9(2), hal. 108-114, 2014.

[9] S. Selin, J. Rikumahu dan R. Patiapon, "Automatisasi Pengerak Pintu Air Pada Bendungan Persawahan Di Kabupaten Buru," J. Simetrik, Vol. 8(1), hal. 68-76, 2018, DOI: 10.31959/Js.V8i1.77.

[10] S. K. Saptomo, R. Isnain and B. I. Setiawan, "Microcontroller System Based Automated Sprinkle Irrigation," J. Irig., Vol. 8(2), pp. 115-125, 2013. 
[11] Y. Yulastri, A. Anton dan I. Ilhamdi, "Rancang Bangun Kendali Pintu Air Secara Otomatis dengan Pemberitahuan Informasi Menggunakan SMS Pada Pengairan Persawahan Berbasis Mikrokontroller," Elektron J. Ilm., Vol. 10(1), hal. 18-22, 2018, Doi: 10.30630/Eji.10.1.85.

[12] I. P. L. Dharma, S. Tansa dan I. Z. Nasibu, "Perancangan Alat Pengendali Pintu Air Sawah Otomatis Dengan Sim8001 Berbasis Mikrokontroler Arduino Uno,” J. Teknik, Vol. 17(1), hal. 40-56, 2019.

[13] A. N. Ariana dan Z. Abidin, "Rancang Bangun Sistem Irigasi Pembibitan Pengkondisian Lahan Padi Berbasis Atmega328 Dan Monitoring Jarak Jauh Dengan Radio Frekuensi 433 Mhz,” J. Tek., Vol. 10(1), P. 999, 2018, DOI: 10.30736/Teknika.V10i1.207.

[14] A. Zulius, "Rancang Bangun Kontrol Pintu Air Otomatis Berdasarkan Level Ketinggian Air Menggunakan Arduino Dan Sensor Hc-Sr04 Pada Dinas PU dan Penataan Ruang Kota Lubuklinggau," J. Sistem Komputer Musirawas, Vol. 2(2), hal. 78-86, 2017.

[15] S. Sadi dan I. S. Putra, "Rancang Bangun Monitoring Ketinggian Air Dan Sistem Kontrol Pada Pintu Air Berbasis Arduino Dan SMS Gateway (Design of Monitoring Water Level Control System Based On Arduino And SMS Gateway)," J. Teknik, Vol. 7(1), 2018. 